\title{
Evaluation of current policy about protected areas in Greece
}

\author{
O. Christopoulou \& E. Kesary \\ Department of Planning and Regional Development, \\ University of Thessaly, Greece
}

\begin{abstract}
Environmental protection currently constitutes an issue of vast importance worldwide. Greece has countersigned a large number of international conventions regarding the protection of the environment, while Greek legislation has already conformed to the relevant European Directives. The establishment of Protected Areas comprises an effective instrument for achieving environmental protection. Therefore, this paper evaluates current national and international environmental policies concerning Protected Areas in Greece. A brief historical review of such policies is also included. Environmental management bodies are being briefly described together with relevant current legislation. Moreover, a critique of environmental policies and their application follows. Finally, amelioration measures are proposed in order to achieve improved and more effective management of Protected Areas in Greece.

Keywords: Greek environmental policy, national, international legislation, protected areas, management bodies.
\end{abstract}

\section{Introduction}

Anthropogenic development is increasingly leading to a shrinking of the natural environment and depletion of natural resources. International community decided to take action by introducing the concept of Protected Areas (PAs), managed areas where human activities are controlled in order to preserve their special environmental and/or cultural characteristics. During the last few decades, special legislation has been formed for their management and protection. In Greece, a complete system of PA protection has not yet been achieved. Policy followed in this field could be characterised as fragmented and ineffective, mainly due to the lack of a successful administrative framework and 
bad application of contemporary legislation. However, Management Bodies (MBs) could play a catalytic role in achieving an economically, socio-politically and technically efficient environmental protection policy regarding PAs. During the last few years there have been several attempts towards planning and founding that goal.

Therefore, this paper is aimed at providing an analytic description of all categories of PAs in Greece, to cite contemporary national and international Greek legislation about PAs accompanied by a brief historic review and, ultimately, evaluate current environmental policy about PAs in Greece and indicate patterns for its amendment in order for it to become more efficient and complete.

\section{National legislation regarding Protected Areas}

Greek fundamental legal framework regarding Protected Areas falls under three main sectors of national policy, the forest policy (Act 86/69 and Act 996/79) the environmental policy (Act 1650/86) and the land-planning policy (Act 2742/99). These policies were formed during different time periods and, as an outcome, are based on different philosophies. They are all in effect but there is no harmonic cooperation between them.

\subsection{Forest policy}

In the first classification of forestal policy, that took place in 1929 with the Act 4173/1929, two important provisions were introduced. Firstly, the institution of "Protective Forests", where according to Article 77 their unconditional safekeeping is essential for national and common good. Secondly, the institution of "Forest Police Device" that are published by the relevant chief forester after the approval of the prefect and can regulate, constrain or forbid any license regarding woodcutting, gathering, pruning or uprooting of trees, shrubs, brushwood and any grass inside farmland, grassland, wooded lands and forests [1].

Act 856/1937 was the first to recognise the need for the protection of PAs and was a turning point in the matters of natural heritage protection. It allowed for the foundation of up to five National Drymoi (National Parks), as areas under a special protection regime, aiming at "flora protection, fauna upgrading and increase, geomorphological formations conservation, natural beauties protection, tourism development and scientific and silvical research". Olympos was the first National Drymos (National Park) founded in 1938 followed by Parnassos in 1939, Parnitha in 1961, Ainos, Samaria [2]. They all fall under the management of the Forest Service.

In 1969, Act 856/1937 was incorporated into the Forestal Code by Act 86/1969 and was later amended with the Act 996/1971. The Forestal Code enabled the designation of specific areas as "Wildlife Refuges (553)", "Controlled Hunting Areas (7)", "Game Breeding Areas (21)" (Act 86/69 as amended by Act 177/75) intending to "protect and preserve the national natural environment and conserve, develop and exploit game and wild fauna". 
Act 996/1971, which is still valid, added five more National Drymoi (National Parks) to the list (Oiti, Pindos, Vikos-Aoos, Sounio, Prespes) and also stated that each can comprise of a central 'core' and a peripheral zone' around it. Moreover, the act extended the protection regime to two more categories of Protected Areas, the "Aesthetic Forests" (19) and the "Preservable Monuments of Nature" (51). Permissible uses and restraints to the development of certain activities in the above categories of PA were determined. Peripheral Forestal Authorities were made responsible for the protection and management of PAs in collaboration with the respective Department of the Central Office of the Ministry of Agriculture.

Finally, according to Act 998/1979 "about the protection of national forests and forestlands" the special protection regime applying to all forests and forestlands extended to PAs. The Act included protection measures for the conservation, development, amelioration and management of forests and forestlands in general, defined their proprietary regime and set terms and conditions under which their use can be altered. It also stressed that all destroyed or degraded forest lands are obligatorily declared reforestable. It was amended by Act 3208/2003 that adjusted the concepts of forest and forestal land [1].

\subsection{Environmental policy}

Regarding environmental policy, Act 1650/1986 "about the protection of the environment" (Frame Law) introduced a break-through to Greek legislation as it incorporated previous laws and enactments relevant to the environment. Thus, it regulated spherically all issues regarding environmental protection such as water, air, land, natural resources, natural ecosystems and cultural environment protection. It could be characterized as a complete enactment, content-wise, due to the accumulated experience of predecessor laws of other states on which it has been based [3]. It amended the overlapping of duties and the environmental legislation fragmentation, promoting horizontal combination of relevant ministries and governmental bodies while enhancing decentralization.

Its aim is "the balanced - viable coexistence of the natural and anthropogenic environment, where natural and cultural protection co-evolve with economic and productive activities". Therefore, the concept of the environmental protection rather than specific area protection was introduced. In more detail, the terms "environment" and "environmental protection" were defined and the goals of such protection were determined. Key tools for the achievement of the abovementioned balanced environmental protection are the Environmental Impact Assessments (EIAs) and the zonation of the PAs, which are now categorised into five new categories:

- Strict Nature Protection Areas

- Nature Protection Areas

- National Parks

- Protected Natural Formations, Protected Landscapes and Elements of the Landscape

- Ecodevelopment Areas 
Characterisation of areas or natural elements as protected, setting their boundaries and their zonation are achieved through a Presidential Decree. Firstly, the importance and uniqueness of them and their species are documented, specific protection and conservation measures are proposed and a Special Environmental Assessment (SEA) is made. The Ministry of Environment, Physical Planning and Public Works is authorized to approve SEAs according to the procedures provided by the recent revise of Act $1650 / 86$ by Act $3010 / 2002$ (article 91) [4].

\subsection{Land-planning policy}

The idea of Management Bodies is included inside Act 1650/86, however, at an early form. The legal form of such Management Bodies is specified by Act 2742/1999 "about Land Planning and Sustainable Development and other provisions" (art 15-17) where the MBs are founded as legal persons of private legal status of non profitable character. Their foundation is obligatory only for National Parks. They are competent for programs, measures and all actions regarding the administration and the function of their area. They can be selffunded through 'bland' development activities. According to article 16, National Drymoi (National Parks), Aesthetic Forests and Monuments of Nature come under the integrated regime of protection of Act 1650/86 for the purpose of their more efficient protection. Whereas, according to article 17, the jurisdictions of the "Natura 2000 Committee" become more extensive in order for it to become the broader body of coordination and surveillance of the administration and management of all PAs in the country and the committee is renamed to "National Committee for the Protected Areas".

By the Act 3044/2002 "about the transfer of building factors and adjustments of other matters regarding the Ministry of Environment, Physical Planning and Public Works (MINENV)" (art. 13) 25 Management Bodies are founded using the National Action Plan for the management of 25 PAs. At present, there are 27 MBs in total. It should be noted that the boundaries of the PAs, their zonation and other land-planning features can now be amended by a Ministerial Decision and not by a Presidential Decree that would take longer. The number and composition of the Management Bodies is determined by a Joint Ministerial Decision [5].

\section{International legislation regarding Protected Areas}

In an attempt to compromise human activities and natural environment conservation, UNESCO carried out, in 1971, the Man \& Biosphere Program. Its purpose was to protect and preserve biosphere resources, in order to conserve the ecosystems, biodiversity and the species in them. In Greece, two areas have been characterized as such: Olympos (3,988 Ha) and Samaria Canyon (4,850 Ha) $(0.07 \%$ of total Greek ground). The General Secretariat of Forests and Natural Environment of the Ministry of Agriculture is the Management Body responsible for the characterization of areas as biosphere reserves [5]. 
The convention for the protection of wetlands of international concern was signed in Ramsar in 1972 and was legalized by Greece with Act 191/1974 and amended by Act 1751/1988 and Act 1950/1991. Its purpose was to protect and conserve wetlands of international interest and all wetlands in general. Out of 340 wetlands in Greece, 11 qualified for the Ramsar category, covering 167.301 hectares $(0.85 \%$ of total Greek ground). All of them have been proposed to be included to the Natura 2000 Network [5].

The convention for the protection of global cultural and natural heritage passed by the UN General Assembly in Paris, in 1972, and was put to action in 1975 , with the purpose of protecting and conserving 'commodities' of global cultural and natural heritage for future generations. In Greece, it was amended by Act 1126/1981 and there have been 14 such 'commodities' recorded. Mounts Antihasia-Meteora (387 Ha) and Mount Athos (33,700 Ha) have been characterized as Mixed Monuments of Global Heritage and cover $0.26 \%$ of the total national ground [4].

The convention for the protection of the Mediterranean for pollution and the Protocol for Specially Protected Mediterranean Areas were signed in Barcelona in 1976 and was legalized in Greece with Act 855/78. It aims for the cooperation of Mediterranean countries in order to prevent, decrease and confront marine pollution. A protocol was included in the convention regarding the creation of Special Protected Mediterranean Areas signed in Geneva in 1982 and legalized in Greece by Act 1634/86. According to the protocol, there are nine coastal and marine protected areas in Greece characterized as SPMAs, covering 260.17 Ha $(0.32 \%$ of total Greek ground).

The convention for the conservation of migratory species of wild fauna, signed in Bonne, in 1979, has not been legalized by Greek legislation until 1999 by Act 2719/1999, but it was being applied earlier, as it has been legalized by the EC Decree 82/46/EC. Its purpose is the conservation of wild migratory fauna for future generations.

The convention for wildlife and European natural habitats conservation, signed in Bern, in 1979, could be characterized as the basis for the creation of 92/43/EC Directive for biotopes. Its goal is the preservation of native flora and fauna and their natural biotopes and the enhancement of the international cooperation for that purpose. It was legalized in Greek legislation by Act $1335 / 83$.

The convention for biodiversity was signed in Rio, in 1992, in the frame of the UN Conference for the environment and development, and legalized in Greece by Act 2204/94. It aims for the conservation and sustainable use of biodiversity 'components' as well as the equal share of benefits from the use of genetic resources.

The convention for fighting off desertification, signed in Paris in 1994 and legalized by Act 2486/94, is indirectly related to the conservation of biodiversity 'components' through taking measures to promote ecosystem protection. It is of great importance since desertification is a major problem in Greece.

79/409 EC Directive for wild birds conservation could be characterized as the first important effort for the conservation of the EC natural environment. 
Its purpose is the conservation of wild birds populations inside the EC and especially of those threatened with extinction, are susceptible to alterations of their biotopes or require special attention due to singularities of their biotopes. The Directive proposed the implementation of measures including the creation of Special Protection Areas (SPAs). The Directive was harmonized to Greek Law with the Ministerial Decision 414985/1985 regarding management measures of wild avifauna. There are 150 Protected Areas characterized as SPAs in Greece at the present [4].

92/43 EC Directive "about the conservation of natural habitats and wild fauna and flora" aims for biodiversity conservation in EC state members through the protection of specific natural habitats of communal interest as well as the conservation of specific flora and fauna species of communal interest. It was released by the European Council as a response to the declaration of the Rio Convention in 1992. It was harmonized to Greek legislation by the Common Ministerial Decision 33318/3028/1998. In order to achieve the goals of the Directive, a network of protected areas called Natura 2000 was created. These areas include either habitats of special communal interest (Annex I of the Directive) or specific species of special interest (Annex II). The Natura 2000 Network falls under a special protection regime specific to each member state, according to its particularities. Every area within the Network is treated separately regarding its special features. Under the Directive, the state has the obligation to examine all projects and activities with potential negative environmental consequences to the specific habitats and species within Special Areas of Conservation (SACs) and take appropriate measures. In more detail, in order to define the zonation and degree of protection in each zone of the areas in question, their mapping takes place using a Special Environmental Assessment followed by a Presidential Decree that defines the degree of protection and the permissible uses. A scientific catalogue, called National Catalogue of the Natura 2000 Network, comprising of 296 such areas was first created by the Greek Center for Biotopes and Wetlands (EKBY) and was later modified by the Ministry of Environment, Physical Planning and Public Works (MINENV) to include 238 SACs today All SACs and SPAs that constitute the network are being run by the Natura 2000 Committee [6].

\section{Protected Areas in Greece}

In Greece, there's a short history regarding the institution of Protected Areas. It was introduced with the Act 856/37 leading to the foundation of the $1^{\text {st }}$ National Park of Olympos in 1938. Today, Greek PAs constitute about 1/5 of the land [7]. According to IUCN, a PA is defined as: "land and/or marine expanse dedicated in the protection of biological diversity and natural and relevant cultural resources, which is subject to management based on legal frames or other effective ways". PAs can be categorised into 6 main categories according to the IUCN categorisation. However, Greece does not follow the specific categorization [8]: 
CATEGORY Ia-Strict Nature Reserve: protected area serving mainly scientific aims.

CATEGORY Ib-Wilderness Area: protected area serving mainly wildlife protection.

CATEGORY II-National Park: protected area aiming mainly at ecosystem protection and recreation.

CATEGORY III-Natural Monument: protected area serving the conservation of specific natural characteristic traits.

CATEGORY IV-Habitat/Species Management Area: protected area aiming mainly at the conservation through administrative intervention.

CATEGORY V-Protected Landscape/Seascape: protected area managed mainly for the conservation of land/marine landscapes and recreation.

CATEGORY VI-Managed Resource Protected Area: protected area managed mainly for the viable growth of natural ecosystems.

\subsection{Protected Areas according to national legislation}

The PA categories according to current national legislation are as follows:

- $\quad$ National Drymoi (National Parks) (Act 856/37 amended by Act 996/71)

- Aesthetic Forests (Act 996/71)

- Preservable Monuments of Nature (Act 996/71)

- Wildlife Refuges (Act 177/75 as amended by Act 2637/98)

- Controlled Hunting Areas (Act 177/75 as amended by Act 2637/98)

- Game Breeding Areas (Act 177/75 as amended by Act 2637/98)

- $\quad$ National Parks (Act 1650/86)

- $\quad$ Strict Nature Protection Areas (Act 1650/86)

- Nature Protection Areas (Act 1650/86)

- $\quad$ Protected Natural Formations and Landscapes (Act 1650/86)

- $\quad$ Ecodevelopment Areas (Act 1650/86)

\subsection{Protected Areas of international magnitude}

Apart from the National Environmental Legislation, Greece, as a member of the EC, has undertaken numerous other specialized obligations in the frame of relevant Conventions, Contracts, Agreements and Directives concerning environmental protection. Moreover, Greece has proposed many areas to be included to the European ecological network of protected areas "Natura 2000" (Special Areas for Conservation and Special Protection Areas). The international magnitude Protected Areas fall into the following categories [5]:

- Wetlands of international magnitude according to Ramsar Convention (Act 191/74 amended by Act 1751/88 and Act 1950/91)

- Natura 2000 network areas (Joint Ministerial Decision $33318 / 3028 / 1998)$

- Special Protection Zones according to the Barcelona Convention (Protocol 4) (Act 855/78 and Act 1634/86)

- Biogenetic Reserves 
- Biosphere Reserves

- Monuments of Worldwide Heritage

- Areas that have been awarded a Eurodiploma

\section{Environmental management bodies}

The outmost relevant bodies in a central level, regarding issues of environmental protection, according to the existing legislation, are the General Secretariat of Forests and Natural Environment (Forest Service) and the General Administration for the Environment - Administration of Environmental Planning of the Ministry of Environment, Physical Planning and Public Works (MINENV).

Act 1650/86 (article 21) provided for the constitution of Management Bodies (MBs) for the PAs but not definitely. It merely mentioned the possibility of "special services". It was Act 2742/99 that attempted to specify and categorize the managing authorities of the PAs explicitly, in chapter E "administration and management of protected areas". The MBs have become legal persons of private legal status, supervised by the Ministry of Environment and Spatial Planning. However, the regulations of article 15 of Act 2742/99, dedicated to the procedures of composition and operation of the MBs, remained inactive for 3 years [7]. The most likely reason is that PAs should be first bordered before being run by a MB. And since characterization and bordering of an area as a PA is usually inhibited by local communities due to the accompanying restrictions, the whole procedure gets canceled or postponed [3].

To overcome the above obstacle, a special provision was incorporated in Act 3044/2002 (article 13), on the Transfer of Development Rights, by which 25 MBs are founded for the management of equivalent national PAs of extreme importance. Two more MBs have been founded since, creating a total of 27.

\section{Evaluation of environmental policies and their application regarding Protected Areas - Proposals}

Greece has fully adopted and incorporated into national legislation all directives and signed conventions relevant to nature protection and biodiversity conservation. However, Greek legal framework on PAs is characterized by structural complexity resulting from the lack of a complete plan regarding the issues of bordering PAs and defining their character on a national level. There have been attempts to restore voids from past legislation with new regulations but new problems emerged, as former legislation has not been cancelled. Today, all Acts regarding environmental protection are still active resulting in a general confusion. Thus, there are delays regarding the application of the regulations and certain provisions may even become practically inactive due to not foreseeing all factors affecting their application.

An important issue is the fact that Greek PAs fall under more than one management authority. Characteristic is the example of forestlands that are under 
the jurisdiction of both the Ministry of Agriculture (through forest legislation), and the Ministry of Environment, Physical Planning and Public Works (through environmental legislation). There are 27 Management Bodies (Act 3044/2002) covering for a total of 238 Special Areas of Conservation (SACs) proposed by the Directive $92 / 34$ and 150 SPAs proposed by the 79/409 Directive. Cooperation between MBs might sometimes be difficult.

The procedure of declaration of PAs under A 1650/86 demonstrates characteristic problems of the legal framework. More specifically, there has been minimal application of Act 1650/86 as 20 years after its adoption it remains to a great extend inapplicable and inactive. Only two areas have been declared protected using the specific act without even defining the actual procedure or management bodies. This is a natural outcome as relevant Presidential Decrees and Ministerial Decisions for the enactment of the categorization of Act 1650/86 have not been forwarded up to date. Additionally, it does not abolish previous legislation regarding the declaration, bordering and management of protected areas. Moreover and most important, proper administration structures, provided either by the Act or the general Greek legislation are still lacking [3]. Finally, public involvement is rather scarce [9]. This reflects the lack of an effective system for the organization and management of Greek natural resources.

Adopting an effective protection system for the PAs also faces the obstacle of public negativity as environmental protection is restricting private land uses. For instance, a significant percentage of the Greek land has been included into the Natura 2000 Network (approx. 16\%). As a result, there have been conflicts between local communities and the government due to the fact that the locals were negative to the restrictions resulting from such categorizations. Moreover, there is no definite policy or planning about admissible and non-admissible actions within the limits of the Natura 2000 Sites. Such uses have only been determined for areas where Special Environmental Assessments and Management Plans have been carried out. In order to turn the public attitude towards environmental protection, local communities should be able to participate in the decision making process and most important they should be informed of the benefits of sustainable development, such as increased tourism activities.

Other issues are the bureaucratic delays, lack of organization in public services and most important lack of "know how" and adequate specialized personnel for the enactment of the management plans. Lack of specialized personnel also results in improper estimation of anthropogenic impacts on the environment. A characteristic example of the delays is the period of 5-7 years needed for the accomplishment of a Special Environmental Assessment that is necessary in order to declare a PA.

Moreover, regarding Directive 92/43, there is a repetition of provisions about game and wild fauna of the Forest Code, in a new text, regarding birds exclusively [1]. Thus, a parallel legislation was created outside the legislative 'tool' covering such matters resulting in confusion and implementation problems. 
Finally, it should be noted that natural habitats and flora / fauna species of communal interest included in Annexes I and II of the 92/43 Directive dot correspond to the massive biodiversity of Greece. A substantial number of types of habitats and endemic and endangered species have not yet been included [10]. Relevant authorities should consider revising the Directive.

In order to amend Greek environmental policy, finalization of the legislation framework about PAs aiming for one final categorization is proposed. The enactment of SACs and SPAs provides such an opportunity as the Natura 2000 Network could be the link between Act 1650/86 and the vast majority of protected areas in Greece. In the future, it could be the 'backbone' regarding biodiversity conservation and environmental protection in general. Additionally, the foundation of extra and more localised MBs is proposed which through the constitution of management plans, where views of stakeholders can be incorporated, will determine precisely admissible and non-admissible activities through zonation eliminating obscurities leading to conflicts and management difficulties.

\section{References}

[1] Kassioumis, K., Nature protection in Greece. Legal framework, protected areas and protection jurisdictions. Geotechnical Scientific Issues, 5(3), pp. 58-74, 1994.

[2] Papageorgiou, K. and Kassioumis, K. The national park policy context in Greece: Park users' perspectives of issues in park administration. Journal for Nature Conservation, 13(4): 231-246.

[3] Beriatos, E., Planning and management of protected areas in Greece: Institutional developments, problems and prospects. Aehoros, 2(1), pp. 58-89, 2003.

[4] Michalopoulou, Ch. Environmental Legislation, Ziti Publishing: Thessalonica, pp. 749-808, 2004.

[5] Christopoulou, O., notes from the MSc subject: Environmental Management and Policy, 2006.

[6] Natura Network 2000; Hellenic Center for Biotopes and Wetlands (EKBY),

Online. www.ekby.gr/ekby.gr/ekby/el/EKBY_Natura2000_el.html

[7] Beriatos, E., Planning and management of protected areas in Greece. Proc. of the $2^{\text {nd }}$ Int. Conf. on Sustainable Development and Planning, eds. A. Kungolos, C.A. Brebbia, \& E. Beriatos, WIT Press: Southampton, pp. 389-400, 2005.

[8] The IUCN Protected Area Management Categories; The World Conservation Union (IUCN), Online. www.iucn.org/programme/ programme/wp2004/wp2004/wpc/pdfs/outputs/pascat/pascatrev_info3.pdf

[9] IUCN, Protected areas of the world: A review of national systems. 2: 184192. Switzerland and Cambridge: IUCN, Gland, 1991.

[10] Greek Areas of Natura 2000 Network; Ministry of Environment, Physical Planning and Public Works (MINENV), Online. www.minenv.gr/ 1/12/121/12103/g1210300.html 